\title{
Efficacy Of Gauze-based Negative Pressure Wound Therapy After Split-thickness Skin Graft In The Care Of Large Wounds
}

\author{
Irfan Ilahi, M. Uzair Ilyas Tahir Kheli, Ehtesham-ul-Haq

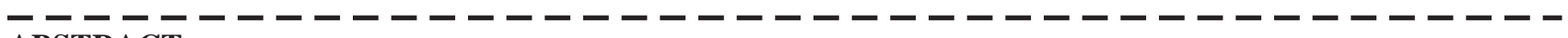

ABSTRACT

Background: Negative-pressure wound therapy (NPWT) or vacuum dressings involve the application of a controlled negative pressure on the wound. Traditionally, STSGs were fixed with bolster technique, where sutures are used to fix pressure dressings over the top of recently placed grafts. Taking it a step further in our study we applied an effective and user friendly filler material (surgical roll gauze) on very large defects. The objective of this study was to assess the clinical efficacy of gauze-based negative pressure wound therapy as an adjunctive therapy to STSG, over complex and very large wounds.

Material \& Methods: This descriptive study was conducted at Army Burn Center, Combined Military Hospital Kharian and PNS Shifa Hospital Karachi from January 2016 to June 2017. Gauze based VAC system used. Negative pressure was applied at $-80 \mathrm{~mm} \mathrm{Hg}$. Evaluation was carried out to assess the performance of gauze-based NPWT.

Results: Total of 63 patients, 42 males and 21 females, with mean age of 32 years SD+15 were included in the study. The wound size included in the study ranged from $12 \times 10 \mathrm{~cm}$ to $88 \times 66 \mathrm{~cm}$. Mean duration of NPWT dressings was 15 days and 313 dressings were employed in total with satisfactory healing achieved in 3 to 4 VAC dressings in most of the cases. Mean duration of hospital stay was 23.92 days at which point graft uptake percentage was in the range of $90 \%(\mathrm{n}=7)$ to $100 \%(\mathrm{n}=20)$. Only $3.2 \%(\mathrm{n}=2)$ cases required partial re-grafting for complete coverage of residual wounds.

Conclusion: Gauze-based Negative-pressure wound therapy over split thickness skin graft is a cost-effective addition to the care and management of large and complex wounds.

KEY WORDS: Skin graft; Vacuum Assisted Closure; Complex wounds;

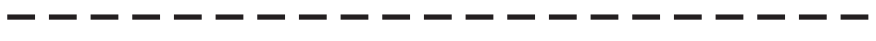 INTRODUCTION}

Negative-pressure wound therapy (NPWT) or vacuum dressings involve the application of a controlled negative pressure on the wound, a method invented in Germany in $1987^{1}$, (when applied for growth of granulation tissue in open fractures, and standardized). It was patented, and published in the United States in 1997 when Morykwas \& Argenta studied the use of suction applied to polyurethane foam in wounds ${ }^{2}$.

In NPWT, also called sub-atmospheric pressure therapy, vacuum assisted closure (VAC), vacuum sealing, vacuum pack therapy, and sealing aspirative therapy, the subatmospheric pressure was directed at the surface of the wound through an interface (polyurethane sponge / gauze), allowing distribution of the negative pressure and use of

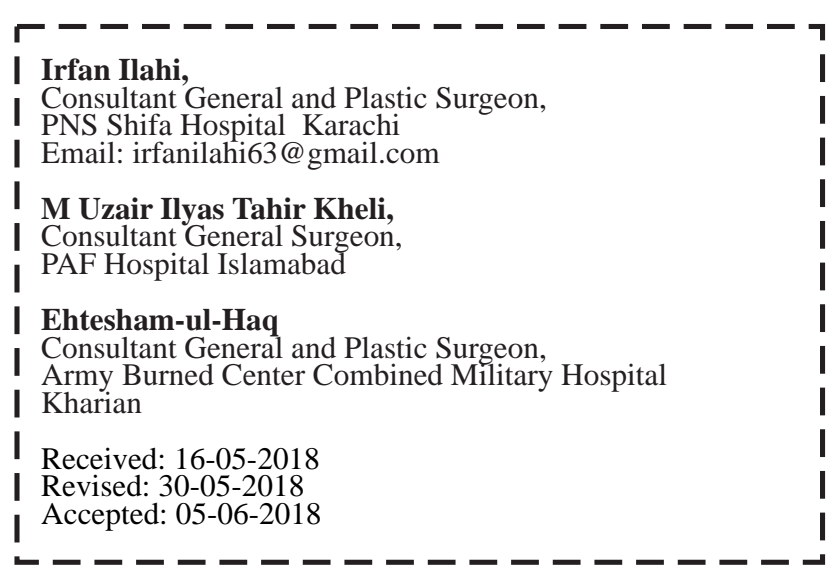

either a constant or intermittent mode of pressure application ${ }^{3}$. Further utilizing the capabilities of NPWT when it is applied over the split-thickness skin graft (STSG) it proved effective in removal of serous fluid which improved protection against infections that can prevent graft take if allowed to accumulate underneath the graft ${ }^{4}$. Also better immobilization of the graft was achieved in anatomically challenging areas (with complicated wound geometries, irregular wound surfaces or wounds subject to movement e.g. joint proximity) ${ }^{5}$. All the above measures improved the close approximation of graft to the wound bed significantly improving graft take . $^{6}$

Traditionally, STSGs were fixed with Bolster technique, where sutures are used to fix pressure dressings over the top of recently placed grafts. Taking it a step further in our study we applied an effective and user friendly filler material (surgical roll gauze) on very large defects, which really pose challenge to the cost of wound care of complex wounds for prolonged period.

The objective of this study was to assess the clinical efficacy of gauze-based negative pressure wound therapy as an adjunctive therapy to STSG, over complex and very large wounds.

\section{MATERIAL AND METHODS}

Very large and complex wounds which were expected to heal over prolonged time with post healing sequelae, wounds infected with resistant organisms with persistent discharge rendering inability to successful graft uptake, presence of 
wounds with co-morbidity, extensive war wounds with limited alternate reconstructive options were included in the study. The wounds with underlying vascular repairs, osteomyelitis, or requiring flaps for effective coverage were excluded.

The wound debridement was carried out to prepare the wound bed prior to graft application. The graft was meshed at a 1:1.5 ratio and stapled to the wound bed. (Fig. 1). After graft placement, paraffin gauze was placed. The graft was then covered with layers of sterilized gauze and tubing of redivac drain with second layer of gauze over it. Finally sealed with Op-site dressing after applying tincture Benzoinco to enhance the adhesiveness of Op-site. The tube was then connected to portable suction machine ensuring negative pressure of 80 to $100 \mathrm{~mm}$ of $\mathrm{Hg}$. The vacuum was set to suction for 10 minutes after every 50 minutes. In more complex wounds with less preparation suction protocol was $5 \mathrm{~min}$ suction after every $25 \mathrm{~min}$. Same protocol was followed during night where possible. Dressings were changed on every third or fourth day.

Upon removal of the NPWT dressing, the graft site was evaluated to ascertain the "success of graft uptake" (a subjective measurement based on clinical judgment) and a separate assessment of the approximate percentage area of successful and unsuccessful graft take was recorded (an objective measurement of graft success (Fig. 1). Graft sites were subsequently dressed-up with gauze dressing and patients were followed in outpatient clinic weekly after discharge from the hospital.

Data relating to patient demographics, comorbidities, duration, wound management and subsequent outcome was recorded for all patients. Continuous data with normal distribution were summarized using means and standard deviations (e.g. patient age) and medians and ranges were calculated where data did not follow a normal distribution (e.g. wound duration). Categorical data such as patient gender was calculated using frequency distributions.

\section{RESULTS}

The study included 63 patients, $42(66.7 \%)$ males and 21 $(33.3 \%)$ females, with male to female ratio of $2: 1$. The mean age of patients was 32 years $\mathrm{SD}+15$.

Among these, 13 patients were suffering from diabetes mellitus and 2 with hypertension. Two of the patients were having concomitant genitourinary injuries causing fecal contamination of the wounds. Table 1 : Results Summary

The wound size ranged from $12 \times 10 \mathrm{~cm}$ to $88 \times 66 \mathrm{~cm}$. Fiftyseven wounds were having moderate $(\mathrm{n}=34)$ to high $(\mathrm{n}=$ 23) amount of exudate in the wound bed. Mean of 8 days $\mathrm{SD}+5($ Range $=25)$ were required for wound preparation before placement of STSG.

The mean duration of NPWT dressing post-operatively was 15 days and 313 dressings were employed in total.
Satisfactory healing was achieved in 3 to 4 VAC dressings in the majority of cases.

The graft uptake percentage was encouraging with $90 \%$ uptake in 7 cases, $95 \%$ uptake in 12 cases, $96 \%$ uptake in 6 cases, $98 \%$ uptake in 12 cases, and $100 \%$ uptake in 20 cases. In 4 cases there were difficulties of application of VAC dressing and 3 cases had surgical site infections postoperatively but with no untoward sequelae. Only 2 (3.2\%) cases required re-grafting for complete coverage of the wounds.

Mean stay in the hospital was 24 days SD+19 with 4 patients having an extended stay of 40 to 60 days and only 2 cases had a stay over 100 days. The limitation was the need of suction apparatus which required hospital stay.

An essential observation during the study was the low cost of the whole system of VAC, as $54(85.7 \%)$ patients had to bear dressing charges of less than PKR (Pakistani Rupee) 5,000 , seven $(11.1 \%$ ) between 5,000 and 10,000 and only $2(3.2 \%)$ patients more than PKR 10,000.

\section{DISCUSSION}

Large wounds with skin loss is a nightmare for the patients as well as the treating surgeons as it prolongs the duration of treatment and are subject to various complications on the way to healing. Our study included wounds with enormous sizes and complications as evident in the figures (Fig 1 \& 2) but with introduction and modification of VAC over graft and effectively reducing the cost by inclusion of commonly available sterilized surgical gauze was our mainstay modality to achieve the successful outcome.

Martinov et $\mathrm{al}^{7}$ followed a case of wound secondary to necrotizing fasciitis for 10 years before declaring a successful outcome as perineal necrotizing fasciitis complicates the situation with contamination by feces and urine. We were able to deal a very complex perineal wound with the same environment in a shorter time and its successful outcome is evident in Fig. 2 (slide 3).

The logical benefits of employing VAC dressings in a wound include arterial vasodilation ${ }^{8}$, stimulation of vascular proliferation ${ }^{9}$, increase in local blood flow ${ }^{10}$, drainage of exudates, removal of edema ${ }^{11}$, reduction in bacterial colonization as shown by Acosta et $\mathrm{al}^{12}$ and similar environment is the basic requirement for successful graft uptake at recipient site. Azzopardi et $\mathrm{al}^{13}$ were able to show the evidence of decreased inflammation, and creation of a moist microenvironment beneficial to wound closure and influencing the shape and growth of the surface tissues in a way that helps healing. All these important factors for the successful graft-take make VAC an important adjunct to be used along STSG with complementary benefits.

Twelve patients in our study had wounds secondary to deep burns and underwent successful STSG with VAC after tedious wound preparation a finding similar to the study 
Efficacy Of Gauze-based Negative Pressure Wound Therapy After Split-thickness Skin Graft In The Care Of Large Wounds

\begin{tabular}{|c|cc|cc|ccc|cc|cc|}
\hline & \multicolumn{2}{|c|}{ Comorbid } & Exudate Levels & \multicolumn{2}{c|}{ Graft Uptake } & \multicolumn{2}{c|}{ Complications } & \multicolumn{2}{c|}{ Re-grafting } \\
\cline { 2 - 13 } & None & DM & High & Moderate & $95 \%$ & $98 \%$ & $100 \%$ & None & SSI & Yes & No \\
\hline Number of Cases & 44 & 13 & 23 & 34 & 12 & 12 & 20 & 56 & 3 & 2 & 61 \\
\hline Percentage & 69.8 & 20.6 & 36.5 & 54 & 19 & 19 & 31 & 89 & 5 & 3 & 97 \\
\hline Total & \multicolumn{10}{|c|}{60} \\
\hline
\end{tabular}

1: (RTA) DEGLOVING INJURY - RIGHT LEG

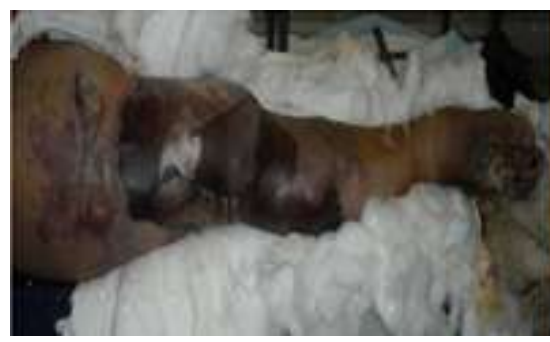

4: APPLICATION OF VAC OVER STSG (LATERAL)
2: DEBRIDEMENT - WOUND PREPARATION

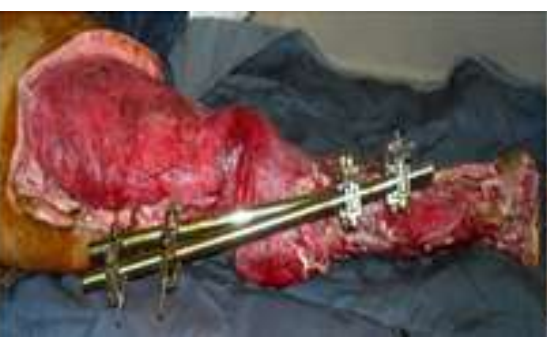

5: APPLICATION OF VAC OVER STSC (MEDICAL)
3: APPLICATION OF STSG

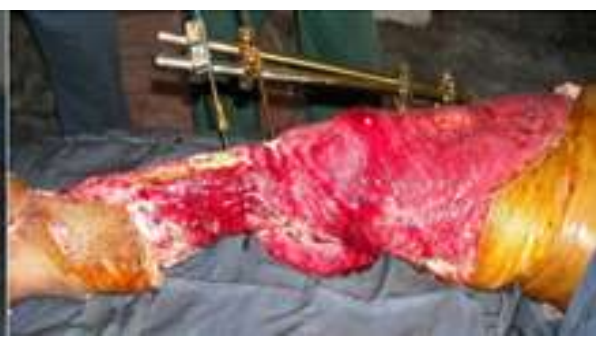

6:GRAFT SITE ON POST OPERATIVE DAY 7

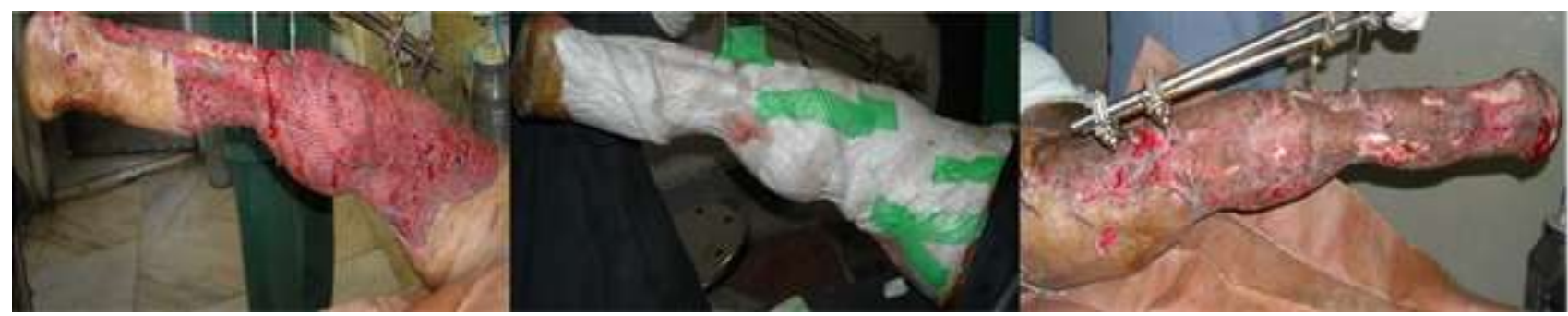

Figure 1: Method of wound preparation and VAC application over graft.

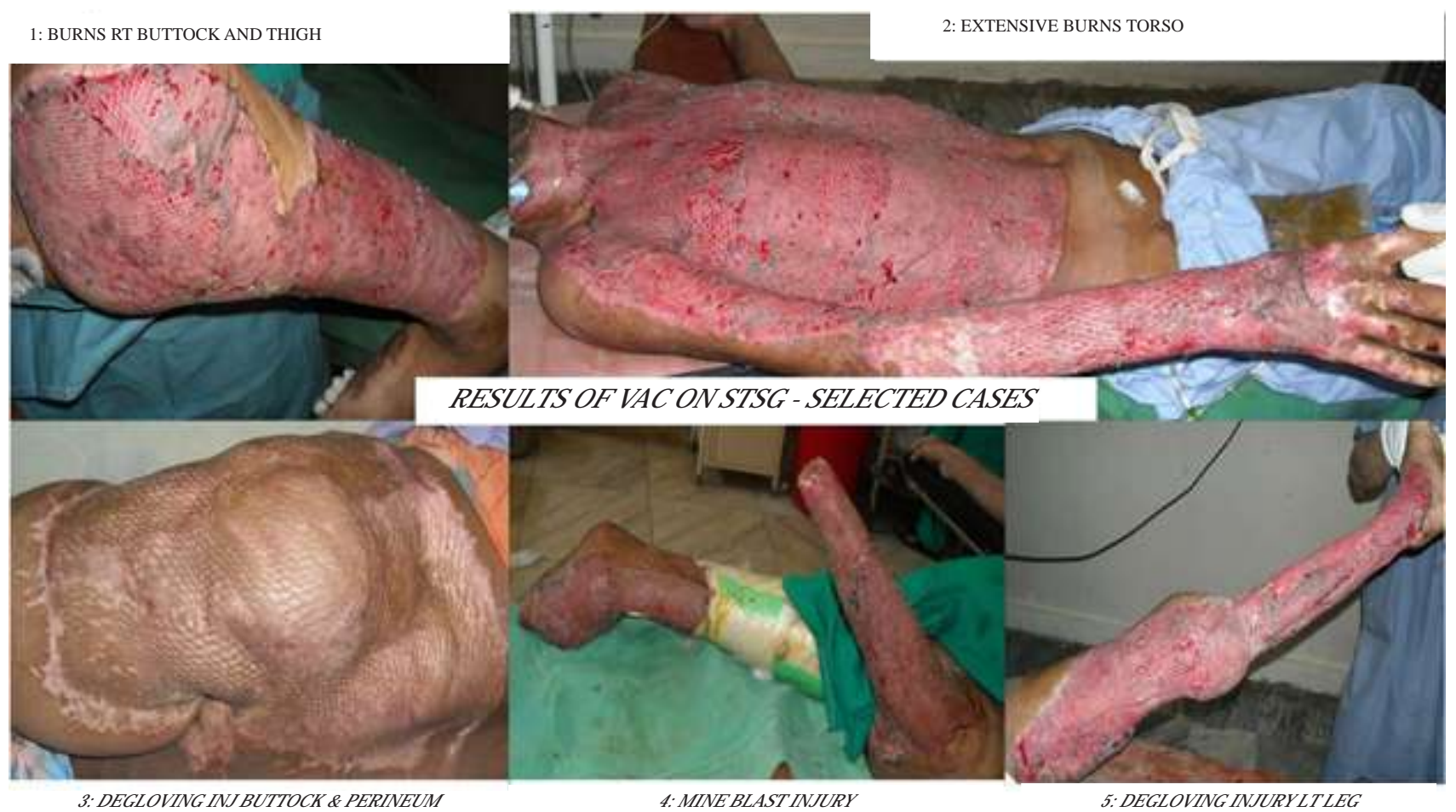

Figure 2: Outcome of selected cases at various stages. 
carried out by Kantak et a ${ }^{14}$ as they observed improved rate of revascularization of dermal substitutes and promotion of re-epithelialization of donor sites when wounds were applied with VAC dressings.

The advanced technology associated with the patent VAC dressing module (V.A.C. Granufoam, KCI, San Antonio, Texas) ${ }^{15}$ makes these devices too complex for routine use due to increased cost of hospitalization and lack of training and motivation of the patient to use them which required further studies testing modifications enabling easy handling for the patients and attendants but without compromise on results $^{16}$.

When dealing with extensive wounds, sterilized polyurethane foam is not easily available hence renders it unusable for frequent change of dressings, on the other hand surgical roll gauze is available in abundance in sterilized form and proves to be cost-effective when wound dressings need to be applied frequently.

Zhao $\mathrm{JC}^{17}$ combined hypertonic glucose along with VAC dressings to reduce the rate of infection at the recipient site with slight benefit but introduction of the fluid in the wound bed needed further processing and preparation and difficult to keep the fluid in the wound bed along application of vacuum. Similarly other modifications like silver-impregnated dressings as done by Bukovcan et $\mathrm{al}^{18}$ and antimicrobialimpregnated dressings by Wu et al ${ }^{19}$ to improve the outcome, although we were able to achieve comparable results but when it comes to risk cost benefits the simplicity and effectiveness, with improved outcome, achieved with gauze was unmatchable.

Furthermore, surgical roll gauze is sterilized with less bulk when compared to the unsterilized foam causing less pressure to the covering opsite. It is easy to apply and forgiving of complicated wound geometries so it could be an ideal material in this condition ${ }^{20}$. Also if vacuum of the dressing fails surgical gauze can give you time to change the dressing at convenience as there is no threat of surgical site infection by the synthetic un-sterilized material like foam. Also sterilized surgical gause is readily and abundantly available commodity in all the operation theaters everywhere.

There was only one case with poor graft uptake (80\%) as multiple factors were involved including continuous fecal discharge nearby causing frequent infections, graft necrosis and frequent leakage of the vacuum due to difficult wound geometry in the area of perineum. (Fig. 2) A remarkable study in this regard was carried out by Lee et $\mathrm{al}^{21}$ which involved majority of patients with perineal wounds and all were successfully treated with negative pressure therapy. This was also evident in the case report published by Vindigni $\mathrm{V}$ et $\mathrm{al}^{22}$ when they treated a 42 -year-old female with fournier's gangrene by NPWT.

Barendse-Hofmann et $\mathrm{al}^{23}$ published an article in 2009 where he presented the circumferential application of VAC for a degloving injury, we were also able to produce the successful outcome of circumferential VAC application with more ease and lesser cost as evident in Fig. 1.

Although NPWT dressings and devices are more expensive than other wound-care products, cost-effective analysis as done by Koncar et $\mathrm{al}^{24}$ and Delhougne $\mathrm{G}$ et $\mathrm{al}^{25}$ shows lower treatment expenses when used judiciously and with careful patient selection.

\section{CONCLUSION}

Gauze-based negative pressure wound therapy over split thickness skin graft is an effective addition to the care and management of large and complex wounds.

\section{REFERENCES}

1. Treatment of infection by vacuum sealing. Fleischmann W, Lang E, Russ M. Unfallchirurg. 1997; 100(4):301-4.

2. Argenta LC, Morykwas MJ. Vacuum-assisted closure: a new method for wound control and treatment: clinical experience. Ann Plast Surg 1997; 38: 563-76.

3. Negative pressure wound therapy: an evidence-based analysis. Ont Health Technol Assess Ser. 2006; 6(14): 1-38.

4. Fischer S, Wall J, Pomahac B, Riviello R, Halvorson EG. Extra-large negative pressure wound therapy dressings for burns - Initial experience with technique, fluid management, and outcomes. Burns 2016; 42: 457-65.

5. Kamolz LP, Lumenta DB, Parvizi D, Wiedner M, Justich I, Keck M, et al. Skin graft fixation in severe burns: use of topical negative pressure. Ann Burns Fire Disasters 2014; 27: 141-5.

6. Petkar KS, Dhanraj P, Kingsly PM, Sreekar H, Lakshmanarao A, Lamba $S$, et al. A prospective randomized controlled trial comparing negative pressure dressing and conventional dressing methods on split-thickness skin grafts in burned patients. Burns 2011; 37: 925-9.

7. Martinov S, Ortiz S. Ten-year follow-up of a case of necrotizing fasciitis successfully treated with negative-pressure wound therapy, dermal regeneration template application, and splitthickness skin autograft. Acta Chir Belg 2017: 1-5.

8. Erba P, Ogawa R, Ackermann M, Adini A, Miele LF, Dastouri $\mathrm{P}$, et al. Angiogenesis in wounds treated by microdeformational wound therapy. Ann Surg. 2011;253(2):402-409.

9. Seo SG, Yeo JH, Kim JH, Kim JB, Cho TJ, Lee DY. Negativepressure wound therapy induces endothelial progenitor cell mobilization in diabetic patients with foot infection or skin defects. Experimental \& molecular medicine. 2013; 45: e62.

10. Scherer SS, Pietramaggiori G, Mathews JC, Prsa MJ, Huang $\mathrm{S}$, Orgill DP. The mechanism of action of the vacuum-assisted closure device. Plast Reconstr Surg. 2008;122(3):786-797.

11. Plikaitis CM, Molnar JA. Subatmospheric pressure wound therapy and the vacuum- assisted closure device: basic science and current clinical successes. Expert Rev Med Devices. 2006; 3(2): 175-184.

12. Acosta S, Bjorck M, Wanhainen A. Negative-pressure wound therapy for prevention and treatment of surgical-site infections after vascular surgery. Br J Surg 2017; 104: e75-e84.

13. Azzopardi EA, Boyce DE, Dickson WA, Azzopardi E, Laing $\mathrm{JH}$, Whitaker IS, et al. Application of topical negative pressure (vacuum-assisted closure) to split-thickness skin grafts: a 
structured evidence-based review. Ann Plast Surg 2013; 70: 23-9.

14. Kantak NA, Mistry R, Halvorson EG. A review of negativepressure wound therapy in the management of burn wounds. Burns 2016; 42: 1623-33.

15. Sachsenmaier S, Peschel A, Ipach I, Kluba T. Antibacterial potency of V.A.C. GranuFoam Silver((R)) Dressing. Injury 2013; 44: 1363-7.

16. Kamamoto F, Lima ALM, Rezende MR, Mattar-Junior R, Leonhardt MC, Kojima KE, Santos CCD. A new low-cost negative-pressure wound therapy versus a commercially available therapy device widely used to treat complex traumatic injuries: a prospective, randomized, non-inferiority trial. Clinics (Sao Paulo). 2017; 72(12): 737-742.

17. Zhao JC, Xian CJ, Yu JA, Shi K, Hong L. Hypertonic Glucose Combined with Negative Pressure Wound Therapy to Prepare Wounds with Pseudomonas aeruginosa Infection for Skin Grafting: A Report of 3 Cases. Ostomy Wound Manage 2015; 61: $28-44$

18. Bukovcan P, Koller J, Hajska M, Zahorec P. Clinical Experience With the Use of Negative Pressure Wound Therapy Combined With a Silver-impregnated Dressing in Mixed Wounds: A Retrospective Study of 50 Cases. Wounds 2016; 28: 255-63.
19. Wu CC, Chew KY, Chen CC, Kuo YR. Antimicrobialimpregnated dressing combined with negative-pressure wound therapy increases split-thickness skin graft engraftment: a simple effective technique. Adv Skin Wound Care 2015; 28: 21-7.

20. Mansoor J, Ellahi I, Junaid Z, Habib A, Ilyas U. Clinical evaluation of improvised gauze-based negative pressure wound therapy in military wounds. Int Wound J. 2015; 12(5): 55963.

21. Lee KT, Pyon JK, Lim SY, Mun GH, Oh KS, Bang SI Negative-pressure wound dressings to secure split-thickness skin grafts in the perineum. Int Wound J 2014; 11: 223-7.

22. Vindigni V, Scarpa C, Dalla Venezia E, Bassetto F. Fournier's Gangrene and Negative Pressure Wound Therapy: A Case Report. Wounds. 2016; 28(10): E41-E43.

23. Barendse-Hofmann MG, van Doorn L, Steenvoorde P. Circumferential application of VAC on a large degloving injury on the lower extremity. J Wound Care 2009;18:79-82.

24. Koncar I, Cvetkovic S, Dragas M, Pejkic S, Lazovic G, Banzic I, et al. Vacuum-assisted wound closure in vascular surgery-clinical and cost benefits in a developing country. Vojnosanit Pregl 2016;73:9-15

25. Delhougne G, Hogan C, Tarka K, Nair S. A Retrospective, Cost-minimization Analysis of Disposable and Traditional Negative Pressure Wound Therapy Medicare Paid Claims. Ostomy Wound Manage. 2018; 64(1): 26-33 